\author{
V. Kim Comfort MD, William E. Code MD FRCPC, \\ Michael E. Rooney BSP, R.W. Yip MD FRCPC
}

\title{
Naproxen premedication reduces postoperative tubal ligation pain
}

This study evaluated the effectiveness of naproxen sodium oral premedication in reducing postoperative pain, analgesic requirements and day surgery length of stay in patients undergoing outpatient laparoscopic tubal ligations. We undertook a randomized, double-blind clinical trial on ASA I and ASA II patients undergoing outpatient laparoscopic tubal ligations. The treatment group received two capsules containing naproxen sodium. $275 \mathrm{mg}$ each, and the control group received two identical capsules containing placebo. Postoperative visual analogue pain scores, analgesic requirements, side-effects and length of day surgery stay were studied. Forty-four patients completed the study with 21 patients in the naproxen group and 23 in the placebo group. There was a statistically significant difference between groups in terms of pain score (naproxen group $0.9 \pm$ 0.2 vs placebo group $3.5 \pm 0.6$ ); patients requiring postoperative opioids (naproxen group 0\% vs placebo group 34.8\%); and time spent in the day surgery unit (naproxen group $168 \pm 13$ min vs placebo group $188 \pm 15 \mathrm{~min}$ ). There was no difference in the incidence of nausea and vomiting. Only one person developed a side-effect from the naproxen sodium which was minor gastric discomfort. This study shows that naproxen decreased the postoperative tubal ligation pain with less subsequent postoperative analgesic requirements, less time to street fitness and no increase in analgesic side-effects. We recommend the use of this premedication in outpatient laparoscopic tubal ligations.

Le but de la présente étude était de déterminer si le naproxen sodique donné avant une ligature tubaire par laparoscopie diminuait la douleur, les besoins analgésiques et le séjour

\section{Key words}

ANAESTHESIA: outpatient;

ANALGESICS: naproxen;

PAIN: postoperative;

PREMEDICATION.

From the Department of Anaesthesia, Royal University Hospital, Saskatoon, Saskatchewan, S7N 0X0.

Address correspondence to: Dr. V. Kim Comfort, Department of Anaesthesia, Royal University Hospital, Saskatoon, Saskatchewan, S7N $0 X 0$.

Accepted for publication 27th December, 1991. hospitalier postopératoires. Dans cette étude à double insu, 44 patientes externes avec un état physique ASA I ou II ont été réparties de façon aléatoire en un groupe traitement $(n=21)$ et un groupe contrôle $(n=23)$. Les patientes traitées (groupe $N$ ) ont pris deux comprimés de naproxen sodique de $275 \mathrm{mg}$ au moins une heure avant la chirurgie alors que celles du groupe contrôle (groupe C) ont reçu deux comprimés de même format, mais contenant un placebo. Les paramètres évalués comprenaient la douleur postopératoire déterminée par échelle analogue visuelle, les besoins analgésiques, les effets secondaires, ainsi que la durée du séjour en salle de réveil et dans l'unité de chirurgie d'un jour. Les résultats ont démontré des différences significatives entre les groupes pour le décompte d l'échelle de la douleur $(0,9 \pm 0,2$ pour le groupe $N$ versus $3,5 \pm$ 0,6 pour le groupe $C$ ), le nombre de patientes nécessitant des narcotiques après la chirurgie $10 \%$ dans le groupe $N$ versus $34,8 \%$ dans le groupe $C)$, et la durée du séjour dans l'unité de chirurgie d'un jour $(168 \pm 13$ min pour le groupe $N$ versus 188 \pm 15 min pour le groupe $C$ ). L'incidence de nausées et vomissements était comparable entre les groupes. Une seule patiente a présenté une réaction au naproxen sodique, soit un léger brûlement épigastrique. Cette étude démontre que le naproxen diminue la douleur, les besoins analgésiques et le séjour hospitalier postopératoire après ligature tubaire par laparoscopie. Nous recommandons une prémédication avec naproxen pour cette chirurgie.

The goals of outpatient anaesthesia are to produce minimal residual effects, good analgesia and a quick return to street fitness. To accomplish this, anaesthetic drugs need to be short acting with minimal side-effects. In addition, analgesics should have an appropriate duration of action yet produce minimal sedation. Postoperative pain can be a major determinant in the recovery time of patients undergoing laparoscopic tubal ligation. ${ }^{1}$ This pain is believed to result from prostaglandin released from the traumatized Fallopian tube, which leads to uterine contraction and a cramp-like lower abdominal pain. ${ }^{2}$ Therefore, prostaglandin inhibition by the nonsteroidal anti-inflammatory drug (NSAID) naproxen sodium should reduce the pelvic pain experienced by these patients after surgery. Naproxen sodium has been found to be effective in the treatment of menstrual cramps in oral doses of $500 \mathrm{mg}$ every six 
hours. ${ }^{3}$ Ideally, their use would lead to reduced opioid requirements and a decreased length of stay in the day surgery unit.

This study was designed to evaluate the role of oral naproxen sodium $550 \mathrm{mg}$ in reducing postoperative pain, analgesic requirements and day surgery recovery time.

\section{Methods}

After institutional ethics approval, a randomized, doubleblind, prospective study was conducted with consenting ASA I and II patients undergoing outpatient laparoscopic tubal ligation under general anaesthesia. Patient exclusion criteria included allergies to NSAIDs, history of peptic ulcer disease, and bleeding disorders. Patients received two identical capsules consisting of either placebo or naproxen sodium $275 \mathrm{mg}$ (total dose $550 \mathrm{mg}$ ) no less than one hour before operation.

The perioperative opioid administration was controlled. No opioids were given for premedication. During anaesthesia fentanyl $\left(2 \mu \mathrm{g} \cdot \mathrm{kg}^{-1}\right)$ or alfentanil $\left(20 \mu \mathrm{g} \cdot \mathrm{kg}^{-1}\right)$ were administered only at induction of anaesthesia. Postoperative analgesia was given on demand by nurse's assessment of patient's pain, level of consciousness and vital signs. It took the form of parenteral morphine or demerol or oral acetaminophen with or without codeine. Induction and maintenance anaesthetic agents were at the discretion of the attending anaesthetist.

Pain scores (PS) were measured by Visual Analogue Score ${ }^{4}$ preoperatively (PSO) and at one (PS1) and two (PS2) hours after the start of the procedure. Patients were then followed up by telephone the next day. The PSO was zero in all but one patient, PS1 reflected the immediate postoperative pain prior to analgesics and was felt $a$ priori to be the most reliable time to measure naproxen's potential efficacy, confounded the least by significant residual anaesthetic effects and before supplemental analgesics. The PS2 reflected pain after analgesics with the residual effects of the anaesthetic being minimized. All opioid and other analgesic use was recorded as were episodes of nausea and vomiting.

Data was analyzed by the Wilcoxon Rank Sum test for comparison of pain scores between the treatment group and the control group. The independent $t$ test was used to analyze recovery and day surgery times between groups and the chi square test with Yates' correction was used to analyze differences between groups in regards to demographic data, nausea/vomiting and complications. A $P$ value of $<0.05$ was considered statistically significant. All data were recorded with $\pm \mathrm{SEM}$.

\section{Results}

Fifty-nine patients were approached to enter the study. Six declined for personal reasons and six were excluded for
TABLE I Demographic data

\begin{tabular}{lccl}
\hline & $\begin{array}{l}\text { Treatment } \\
\text { group }\end{array}$ & \multicolumn{1}{l}{$\begin{array}{l}\text { Control } \\
\text { group }\end{array}$} & \\
\hline Age (yr) & $31 \pm 1.2$ & $30 \pm 1.3$ & NS \\
Weight $(\mathrm{kg})$ & $65.4 \pm 3.3$ & $68.6 \pm 2.9$ & NS \\
Menses & $4(19.0 \%)$ & $1(4.3 \%)$ & NS \\
Oral & $4(19.0 \%)$ & $7(32.3 \%)$ & NS \\
Contraceptives & $6(28.6 \%)$ & $7(32.3 \%)$ & NS \\
Felsche clips & & & \\
Mean procedure & $46 \pm 4$ & $43 \pm 3$ & NS \\
Duration (min) & $5(24 \%)$ & $0(0 \%)$ & $P<0.05$ \\
Associated procedures & 5 & & \\
\hline
\end{tabular}

NS = nonsignificant.

TABLE II Visual analogue pain scores

\begin{tabular}{llll}
\hline & $\begin{array}{l}\text { Treatment } \\
\text { group }\end{array}$ & $\begin{array}{l}\text { Control } \\
\text { group }\end{array}$ & \\
\hline Pain Score 1 hr & $0.9 \pm 0.2$ & $3.5 \pm 0.6$ & $P<0.05$ \\
(PS1) & $n=21$ & $n=23$ & \\
Pain Score 2 hr & $1.1 \pm 0.2$ & $2.4 \pm 0.5$ & $P<0.05$ \\
(PS2) & $n=21$ & $n=23$ & \\
Pain score & $0.2 \pm 0.1$ & $0.6 \pm 0.2$ & NS \\
next day & $n=17$ & $n=16$ & \\
PS1 & $0.6 \pm 0.3$ & $4.91 \pm 1.2$ & $P<0.01$ \\
Clips & $n=6$ & $n=7$ & \\
PS1 & $1.0 \pm 0.3$ & $1.7 \pm 0.5$ & $P<0.05$ \\
Coagulation & $n=15$ & $n=16$ & \\
\hline
\end{tabular}

medical reasons (active peptic ulcer disease) so that 47 patients were entered. Three patients were excluded from final analysis: two proceeded to laparotomy and one experienced a severe psychological reaction associated with a concomitant therapeutic abortion. Twenty-one patients were randomized to the naproxen group and 23 to the placebo group.

Demographic information (Table I) revealed no differences between the groups. Possible confounding variables such as menses at the time of surgery, the use of oral contraceptive pills (OCP), percentage having Felsche clips versus coagulation, and the procedure length, were not different between the groups. The number of patients having associated procedures performed at the same time as the tubal ligation was greater in the naproxen group than in the placebo group. These procedures included one dilation and curretage, three removal of intrauterine contraceptive devices and one laser therapy of plantar warts in the treatment group.

Visual analogue scores, with zero being no pain and ten being extreme pain, for one hour post (PS1) were made at an average of $61 \mathrm{~min}$ from the start of the procedure in both groups and two hours post (PS2) $132 \mathrm{~min}$ in the naproxen group and $130 \mathrm{~min}$ in the placebo group (Table II) (NS). As can be seen in Table II, the treatment group 
TABLE III Postoperative opioid therapy

\begin{tabular}{llll}
\hline & $\begin{array}{l}\text { Treatment } \\
\text { group }\end{array}$ & $\begin{array}{l}\text { Control } \\
\text { group }\end{array}$ & \\
\hline $\begin{array}{l}\text { Patients requiring } \\
\text { 1 Postoperative parenteral } \\
\text { opioids }\end{array}$ & 0 & $8(34.8 \%)$ & $P<0.05$ \\
$\begin{array}{l}\text { 2 Intrahospital analgesia } \\
\text { 3 Post-discharge analgesia }\end{array}$ & $\begin{array}{l}3(14.3 \%) \\
7(41.2 \%) \\
n=17\end{array}$ & $\begin{array}{l}12(52.2 \%) \\
9(50.0 \%) \\
n=18\end{array}$ & $\begin{array}{l}P<0.05 \\
\text { NS }\end{array}$ \\
\hline
\end{tabular}

TABLE IV Recovery room and day surgery stay

\begin{tabular}{lccl}
\hline & $\begin{array}{l}\text { Treatment } \\
\text { group }\end{array}$ & $\begin{array}{l}\text { Control } \\
\text { group }\end{array}$ & \\
\hline $\begin{array}{c}\text { Mean time (min) } \\
\text { in recovery room }\end{array}$ & $47 \pm 3$ & $50 \pm 5$ & NS \\
$\begin{array}{c}\text { Mean time (min) } \\
\text { in day surgery }\end{array}$ & $168 \pm 13$ & $188 \pm 15$ & $P<0.01$ \\
\hline
\end{tabular}

had lower pain scores postoperatively at both PS1 and PS2. When the groups were divided into subgroups of those receiving Felsche clip tubal occlusion and those receiving coagulation, the pain scores were lower in the naproxen group for both techniques. In the placebo group the pain scores were higher in those having Felsche clips than coagulation $(P<0.05)$.

The number of patients who could be contacted the next day was not different between groups (Table II). Pain scores had regressed to minimal levels in both groups by this time.

The requirement for parenteral opioids (Table III) was lower in the naproxen group with no patient requiring parenteral opioids. In contrast, $34.8 \%$ of the patients in the placebo group received parenteral opioids. Comparison of intrahospital oral analgesic requirements was also less in the naproxen group. There was no difference between groups in the use of post-discharge analgesics.

Only one patient in the naproxen group had a side-effect attributable to the naproxen sodium, namely mild epigastric burning immediately before operation. After surgery, four patients $(19.0 \%)$ in the naproxen group experienced nausea/vomiting versus five patients $(21.7 \%)$ in the placebo group (NS).

Although the mean time spent in the recovery room was not different between groups (Table IV), a shorter time was spent in the day surgery unit postoperatively by those in the naproxen group $(P<0.01)$.

\section{Discussion}

Tubal ligation is associated with considerable postoperative pain ${ }^{1}$ which leads to patient discomfort, nausea and vomiting, and delayed recovery. This pain is relatively brief and resolves in most patients within $24 \mathrm{hr} .{ }^{5}$ Huang et al. examined the efficacy of the NSAID meclofenamate premedication in patients undergoing laparoscopic tubal ligation and demonstrated a decrease in postoperative pain, albeit of short duration due to the short half-life of this drug. However, in their study there was no mention of control of concurrent opioid administration. Local anaesthesia infiltration of the tubes intraoperatively has also been shown to be effective in reducing postoperative pain ${ }^{6}$ but this is also of short duration (up to two hours). Naproxen sodium has been compared with acetaminophen and pentazocine for postoperative pain in a wide variety of surgical procedures and was found to be superior to both in pain control and patient tolerance. ${ }^{7}$ Brown et al. compared naproxen sodium with morphine sulfate and placebo in postoperative surgical pain and found naproxen sodium as effective as morphine in the first hour and superior to morphine at three to six hours after administration. ${ }^{8}$

Naproxen sodium is rapidly absorbed with peak plasma concentration attained within $20-40 \mathrm{~min}$. It has a plasma beta half-life of approximately $14 \mathrm{hr}^{9}$ with a duration of clinical action of about eight hours ${ }^{10}$ making it an excellent choice for the treatment of the pain associated with this procedure. By giving the medication before surgery, therapeutic plasma levels are attained before the tissue damage which may reduce prostaglandin synthesis and prevent the resulting postoperative pain. ${ }^{2}$ Naproxen sodium is a non-narcotic analgesic without the complications of respiratory depression and addiction.

We evaluated 44 patients undergoing outpatient laparoscopic tubal ligation, with a bias against the naproxen group who experienced more concurrent procedures. In spite of this, pain was less in the naproxen group at both measurement times. The observation that the pain experienced by both groups the next day was very low and not different reinforces the concept that this pain is of short duration. Postoperative opioid requirements were reduced in the naproxen group, especially for parenteral narcotics. Post-discharge analgesia requirements were not different but of the seven patients in the naproxen group who required post-discharge analgesia, only one took it for abdominal discomfort. The remaining subjects required analgesia for skeletal muscle pain, sore throats and headaches. In the placebo group seven of the nine patients who required post-discharge analgesia took the medication for abdominal discomfort

Our method of evaluating postoperative pain used objective analgesic requirements and subjective visual analogue scores. In the measurement of pain Huskisson found the visual analogue score the most sensitive of the available tests and this measurement has been found to be reproducible. $^{4}$

Recovery room stays were not different between groups 
in this study. This might be expected as discharge criteria (which in our institute is determined by no less than nine on a modified Aldrete scoring guide) are more dependent upon residual anaesthetic effects. Day surgery time was reduced in the naproxen group by an average of $20 \mathrm{~min}$, but whether this constitutes a clinically important benefit depends upon the situation of practice. Our criteria for discharge are dependent on time after the procedure, last parenteral analgesics, stable vital signs, pain and vomiting control and are assessed by the nurses at regular intervals (10-15 min), but may vary depending on the demand on the nurses' time.

Naproxen sodium and NSAIDs are effective as analgesics in outpatient tubal ligation, as well as for other day surgery procedures such as orthopaedic surgery ${ }^{11}$ and in tonsillectomy. ${ }^{12}$ Further studies are required to evaluate naproxen sodium and other preparations as the only analgesic in an opioid-free anaesthetic.

In summary, premedication with oral naproxen sodium $550 \mathrm{mg}$ before general anaesthesia for outpatient laparoscopic tubal ligation decreased pain, reduced postoperative analgesic requirements, and reduced the length of stay in the day surgery unit without increasing morbidity. Therefore, naproxen sodium is recommended as an effective oral premedication for patients undergoing laparoscopic tubal ligation.

\section{References}

1 Chi I-Cheng, Cole LP. Incidence of pain among women undergoing laparoscopic sterilization by electrocoagulation, the spring-loaded clip, and the tubal ring. Am J Obstet Gynecol 1979; 135: 397-401.

2 Brodie BL, Casper RF. Prostaglandins mediate postoperative pain in Falope ring sterilization. Am J Obstet Gynecol 1985; 151: 175-7.

3 Akerlund $M$, Stromberg $P$. Comparison of ketoprofen and naproxen in the treatment of dysmenorrhoea, with special regard to time of onset of pain relief. Curr Med Res Opin 1989; 11: 485-90.

4 Huskisson EC. Measurement of pain. Lancet 1974; 1: 1127-31.

5 Huang K, Wolfe W, Tsueda K, Simpson P, Caissie $K$. Effects of meclofenamate and acetaminophen on abdominal pain following tubal occlusion. Am J Obstet Gynecol 1986; 155: 624-9.

6 Burney RG, Soni V. Intraperitoneal local anaesthetics for tubal ligation. Regional Anesthesia 1982; 7: 74.

7 Filtzer HS. A double-blind randomized comparison of naproxen sodium, acetaminophen and pentazocine in postoperative pain. Current Therapeutic Research 1980; 27: 293-301.
8 Brown $C$, Sevelius $H$, Wild $V$. A comparison of single doses of naproxen sodium, morphine sulfate, and placebo in patients with postoperative pain. Current Therapeutic Research 1984; 35: 511-8.

9 Runkel R, Forchielli E, Boost G, et al. Naproxen-metabolism, excretion and comparative pharmacokinetics. Scand J Rheumatol 1973; 2: 29-36.

10 Bloomfield S, Barden T, Mitchell J. Analgesic efficacy of naproxen in postpartum pain. Clin Pharmacol Ther 1974; 15: 201.

11 Kvarnes $L$. Naproxen sodium versus pentazocine in treating postoperative pain. Current Therapeutic Research 1989; 46: 259-68.

12 Watters $C$, Patterson C, Mathews H, Campbell W. Diclofenac sodium for post-tonsillectomy pain in children. Anaesthesia 1988; 43: 641-3. 